2016-07-02

\title{
Extending story-worlds through social media
}

\author{
Myers, M
}

http://hdl.handle.net/10026.1/11846

10.1080/13569783.2016.1194193

Research in Drama Education: The Journal of Applied Theatre and Performance

All content in PEARL is protected by copyright law. Author manuscripts are made available in accordance with publisher policies. Please cite only the published version using the details provided on the item record or document. In the absence of an open licence (e.g. Creative Commons), permissions for further reuse of content should be sought from the publisher or author. 


\title{
'Extending Story-worlds through Social Media'
}

\section{Authors: Misha Myers, Dane Watkins and Richard Sobey}

\author{
Affiliation: a. Monash University, AU; b. Falmouth University, UK; c. WildWorks/ \\ University of Leeds, UK
}

\begin{abstract}
Technological innovations in digital communication technologies offer possibilities for new forms of participation and storytelling in theatre. Wildworks Theatre Company creates work that is discovered and devised with partners, artists and community participants in response to specific cultural and geographical locations. The work includes people in roles that can mirror their everyday real life roles inside the performance world. This paper considers findings and interaction methods of research the company pursued with researchers Myers and Watkins. to explore how transmedial methods may extend the reach of story-worlds it creates. The research considered how these methods might help build stronger relationships with communities and enhance experiences of the work for both participants and audience members.
\end{abstract}

Name and email address of corresponding author:

Dr. Misha Myers, misha.myers@monash.edu

\section{Introduction}

Innovations in digital communication technologies make new forms of participation and storytelling possible through a transmedial participatory communication landscape, whereby audiences are invited to interact and contribute content to narrative worlds played out live across multiple media. For example, New Paradise Theatre's Fatebook (2009) was mediated through thirteen fictional Facebook accounts, audiences live-tweeted characters in Mechanical Heart Theatre Company's live stage performance \#Hashtag (2013), six actors tweeted Romeo and Juliet in Royal Shakespeare Company and Mudlark's Such Tweet Sorrow (2010) and audiences interacted and participated in in The Passion, created by National Theatre Wales and WildWorks with Michael Sheen, through live streaming, YouTube and tweets (http://wildworks.biz/projects/the-passion/, 2011). 
WildWorks pursued a continuing interest in the possibilities that changes in digital technologies afford with researchers Myers and Watkins through a series of practical experiments using social media as part of and following on from its theatre performance of "100: The Day Our World Changed" (2014). This exploration developed from the company's desire to extend the reach of the worlds and social networks it creates to build stronger relationships and experiences for participants and audience members alike. This paper considers the findings of those experiments, interaction methods used, and how they developed WildWorks' thinking in relation to social media by moving beyond marketing to consider alternative ways to create, document and develop long-lasting "impact echoes" of its work with audiences (Brown and Ratzin 2011).

\section{Research Focus: Introducing WildWorks}

Each Wildworks performance is 'discovered' and devised in a specific context through strong relationships with partners, artists and community participants developed over time. These often include real people in roles that mirror their real life roles inside the performance world, its narrative and its dramaturgy - welders, farmers, security officers. A team of artists and designers spend time talking and exploring with communities - individuals and groups - to discover personal connections and stories that become amplified in the finished work to create a world that unfolds across a large site including both visually rich scenes played out across large vistas of a landscape (across a valley, for example) as well as performative installations where more intimate interactions and encounters take place, where audiences interact individually with a performer or provide their own personal narratives relevant to the content of the performance.

WildWorks initial interest in digital technologies, and social media especially, came not only as a means for developing a toolbox to create work (i.e. realise effects or atmospheres) but also for sharing information (meetings, rehearsals etc.) across a large number of people involved in the making process. Initially, WildWorks was pushing out messages: tweeting successes, milestones, celebratory moments or points of interest and posting images to support these. However, qualitative research undertaken by the company suggested audiences were very interested in accessing more information about the devising processes. This research included face to face evaluative interviews with both audiences and participants of past shows, in which interviewees were asked about what attracts them to WildWorks' shows and what more would they like to know before attending. 2011's The Passion and 2012's Babel were a particular focus for this research. Such shift from spectatorship to an expectation of participation made WildWorks question how it could deepen experiences for participants and audiences in terms of both the devising work itself and the experience of working alongside the company on particular projects. Similarly to forms of media that enable audiences' immersion in a story (coined 'deep media' by Rose 2011,3 ), theatre audiences can use social media to contribute to atmospheres 
(or actions) in the experience of a world that is happening just once, live and in a collective moment. By enabling the design of an infrastructure and dynamic story-world with space for audiences to participate collectively, social media offered a way for WildWorks to extend the arc of any given experience beyond the time and place of an event, from the devising process, to the performance and beyond (a process termed the 'Arc of Engagement' by Brown and Ratzin 2011). The aim, ultimately, was to build a community of advocates and critics that would promote their own thinking about a particular performance.

To explore practical delivery of the ways WildWorks might use social media to meet its goal, Myers and Watkins worked with Wildworks' Richard Sobey, the research focusing on the performance "100: The Day Our World Changed", a full performative day of remembrance and commemoration to mark the centenary of the outbreak of World War One. The work was created for The Lost Gardens of Heligan in Cornwall and co-commissioned by 14-18 NOW and WW1 Centenary Art Commissions, to mark lives of Cornishmen from surrounding parishes who went to war, leaving their families behind. The title refers to both the centenary and the impact of the first world war on communities. The work was devised and developed within three parishes from which the Cornishmen hailed and the work was performed across the parishes. Most of the 600 participants involved in making and performing in the event came from local communities. The event took place over 12 hours on 3 August 2015 with dispersed activity happening across multiple geographic locations from the harbour of Mevagissey, along a 2.5 mile walk through the town and throughout the 200 acre grounds of the gardens. The research with social media engaged with the event through three experiments corresponding to the three stages involved in the "arc of engagement" referred to previously: participant documentation, heralding, and archive annotation. The digital presence of these experiments did not directly interact with the live event as it was happening, but led up to and followed the event. They invited participants and audiences to engage with narratives introduced in the build up to and devising of the performance and to contribute to reflection on and documentation of the event.

\section{Research Experiments}

\section{A. Participant documentation}

Participants were invited to use Twitter to document their working processes in an effort to understand how a 'constant stream' of feedback could help WildWorks creative thinking and decision-making. Additionally, members of Cornwall Youth Theatre were asked to experiment with tweeting in-character during the build up to the performance. While participating actors enjoyed the process, issues arose around 'who' was tweeting (real life person or character) and what 'account' it came from. Although photos and personal stories of the participants' working experiences were collected after the event, few people shared 
their experiences of the build up process. For example, one participant commented she wanted to be 'in the moment', synchronising with experiences of the performers rather than continually stepping outside to message her colleagues. Nevertheless, a post made on 1 August 2014 on WildWorks' Facebook site promoted the event through the story of local participant Harry Gooby's experience and how he drew inspiration for his performance as a wounded soldier in the event from the story of his great uncle, a soldier who fought in the Great War

[http://wildworks.biz/blog/cornish-soldiers-great-war-captain-roy-molyneux-quilter/]. This post was shared and liked on Facebook and increased traffic to WildWorks' website [https://www.facebook.com/WildWorksTheatre]. Furthermore, it highlighted the potential of social media to showcase individual participant's contributions and build networks and legacy with communities.

\section{B. Heralding}

As a way of introducing the 100 , a novel framework was developed through a series of Twitter feeds (which also fed into Facebook posts) based on characters and storylines relevant to the event, a method WildWorks refers to as 'heralding'. The aim was to initiate dialogue with audiences beforehand and strengthen their relationship to, or understanding of, characters or narratives in the live event. This experiment led to new understandings about dramaturgical and design considerations with transmedial storytelling that had a significant impact on the performance and WildWorks creative working with digital media.

The first heralding tweets were sent from a fictitious gardener William Pill who worked at Heligan during WWI [https://twitter.com/1914Gardener]. These tweets recounted details of the character's fictional day to day life gardening at Heligan in the build up to the war and sometimes included traditional gardening tips, photos and invitations for a dialogue, which received some playful interactions

[https://twitter.com/1914Gardener/status/489746283486130178]. While he was to be a recognisable character on the day of the live performance, Artistic Director Bill Mitchell was concerned that this focus on him in the feed might set up audience expectations for the character to be a main protagonist of the event. However, at the stage of the devising process the feed revealed the opportunity for discovering a fluidity of detail of individual character's lives in the way that audiences might encounter them as they navigated the multiple locations and arc of the day. This method of tweeting in character became a tool for both the company's devising as the work developed and also a mechanism for audiences to discover character detail throughout the performance.

In response to Mitchell's concerns about the Pill character, a new Twitter feed was developed around a motorcyclist character (Figure 1). Originally this character was 
conceived as a device to introduce the announcement of the outbreak of war in the performance by arriving on motorcycle to pass a telegram to the Mayor of Mevagissey with news of the impending war [http://wildworks.biz/blog/1914-motorcyclist/]. With the idea of developing the narrative around this character further, playwright Paul Farmer was commissioned to author 130 tweets sent from the fictitious 1914 motorcyclist (Figure 2) commencing on 3 July 2014. Conceptualised as urgent messages, warnings, signposts sent from a dispatch rider as he journeyed across Europe with news of the impending war, these tweets included background detail not included in the performance and provided an additional layer of information and perspective on the era to prepare an audience in advance of the performance.

While the feed quickly built a wide following, monitoring revealed that tweets were not being re-tweeted. In response, unscheduled messages with historical images and other information connected to the motorcyclist's tweets were added. Importantly, these tweets appealed to a wider global audience, with re-tweets from as far as Argentina and California, far beyond the scope of advertising a performance in Cornwall. Overall, 200 individual accounts interacted with WildWorks Twitter feed in the run up to the performance, while 600 participants were involved in creating the event. The potential reach of the Twitter campaign was calculated at over 134,000 accounts.

An invaluable outcome of this experiment was that the Twitter campaign had a significant impact on the development of the show itself. The experience of tracking the tweets and responses shifted Mitchell's thinking about the potential of the motorcyclist as a mechanism in the show. The character became an essential through-line for the whole performance and the mechanism by which very personal stories of families in the three parishes involved could be connected, not only to the global event that was the opening of WW1, but also to the variety of physical locations for the show (the audience moved across a 2.5 mile performance space; Mitchell 2015: unpaginated).

\section{Archive Annotation}

Since 2005 , over 500,000 people have attended WildWorks performances. While WildWorks has developed a list of 879 email addresses that it essentially used to send email newsletters detailing events, requests and updates, subscribed users were registered to a network that was actually under-utilised. To improve WildWorks database, create a more active network through increased online participation and develop deeper audience communication, this experiment invited members in the list to share experiences, memories, reflections and annotations on WildWorks repertoire [http://www.lab.wildworks.biz/advent-calendar/]. 
Using the convention of an Advent calendar, an email campaign supported by social media was launched after the 100 to capture the subscribed users comments about particular performances and encouraging them to share their own experiences and personal details. Briefly, subscribers received an email each day for 25 days leading up to Christmas 2015 with a cropped picture that encouraged the subscriber to guess the bigger picture, a photograph from a WildWorks performance. Edited and selected to provoke curiosity, a link from the picture gave access to a web page where the full picture was revealed along with questions prompting subscribers to add comments: Where was the image taken? What performance had it captured? Do you remember this? Of the 879 people on the list, 361 opened the email invite, 101 clicked the link, 56 people subscribed to the new advent calendar email list, but only 19 commented on the website.

\section{Conclusions}

While contribution to these digital experiments did not attract the same numbers as a WildWorks performance audience or participants, they led WildWorks to some useful discoveries about working with social media. As Mitchell commented, 'the discussions around the activity and possibilities really helped our thinking about how we can exploit more fully opportunities to play out our narrative across new platforms.... We now think about platforms and ways of creating and augmenting narrative worlds' (Mitchell 2015: unpaginated).

Globally, experiments undertaken shifted WildWorks understanding about the potential of social media as a creative tool for engaging audiences actively in the creation of storyworlds in its site-specific work. The novel heralding experiment had the most impact not only in terms of helping dramaturgical conceptualisation and devising of performances, but also by providing an opportunity for public engagement with the process of making the work. The process of creating the heralding campaign changed WildWorks thinking about the role of the motorcyclist in the performance, becoming a narrative thread throughout, from his first appearance to guiding the crowd from one scene to the next. Not only was he a constant siren that linked deeply personal moments that played out in front of the audience, but he also became the key image for all publicity including posters, flyers and online content (Figure3). This simple and highly effective mechanism would not have been revealed if WildWorks had not made good use of Twitter. The use of such Twitter heralding was considered an invaluable method of sharing information and research that informed artistic 
and design decisions during the creative process. Despite the limited amount of material gathered from participants during and after the devising process, both through the Twitter and email campaigns, exploring archive annotation further using different methods is needed, for example by setting up documentation methods in the form of reflective diaries or blogs. To be successful, however, such methods must be considered the onset of the creative work as part of discussions with partners and commissioners.

While social media offers new forms of creativity, digital platforms for enhancing immersive experience of storyworlds and new ways of connecting with audiences, it requires creative organisations to experiment with the nature of the medium in the same way that they experiment with forms of theatre. Considering new conventions and expectations of audiences is paramount as they adopt these media into their everyday lives.

\section{Acknowledgements}

This research was funded in part by the European Union through the European Social Fund project 'Augmenting Impact with Social Media' (no. 011200NCO5).

\section{Reference List}

Brown, A.S. and R. Ratzin. 2011. Making Sense of Audience Engagement, Volume I: A critical assessment of efforts by nonprofit arts organizations to engage audiences and visitors in deeper and more impactful arts experiences. San Francisco: The San Francisco Foundation.

Mitchell, B. 2015. Informal conversation with author Richard Sobey, 5 August 2015.

Rose, F. 2011. The Art of Immersion: How the Digital Generation is Remaking Hollywood, Madison Avenue and the Way We Tell Stories. New York: W.W. Norton \& Co.

Taylor, M. 2014. Wildworks Theatre, Facebook post, 14 July 2014.

https://www.facebook.com/WildWorksTheatre (accessed 15 April 2016).

\section{Contributors Notes}

Misha Myers is a performance practitioner, researcher and Lecturer at Monash University. Her research is focused on enabling social change through participatory, located and digital performance. She is Principal Investigator on the European Social Fund project 'Augmenting Impact with Social Media'.

Dane Watkins is a creative technologist starting a practice-based PhD at Falmouth University and was Research Assistant on 'Augmenting Impact with Social Media' funded by the European Social Fund. 
Richard Sobey is an international strategic planning consultant, working across the cultural, heritage, urban planning and land management sectors. Formerly Executive Director at WildWorks, he is also Director of International Strategic Initiatives at the Global Arts Agenda and a Research Fellow in the University of Leeds' School of Performance and Cultural Industries. 

